\title{
NSD2 is downregulated in T2DM and promotes $\beta$ cell proliferation and insulin secretion through the transcriptionally regulation of PDX1
}

\author{
SUQIN SHI ${ }^{1,2}$, LU ZHAO 3 and LILI ZHENG ${ }^{1}$ \\ ${ }^{1}$ Department of Endocrinology, The First Affiliated Hospital of Zhengzhou University, Zhengzhou, Henan 450052; \\ ${ }^{2}$ Department of Endocrinology, The First Affiliated Hospital of Henan University of TCM, Zhengzhou, Henan 450000; \\ ${ }^{3}$ Department of Endocrinology, The Third Affiliated Hospital of Henan University of TCM, \\ Zhengzhou, Henan 450004, P.R. China
}

Received February 10, 2018; Accepted June 27, 2018

DOI: $10.3892 / \mathrm{mmr} .2018 .9338$

\begin{abstract}
Diabetes has become a major public health issue in the world. Type 2 diabetes mellitus (T2DM), also known as non-insulin-dependent diabetes mellitus, has been identified to result in an inability to compensate for insulin resistance. A previous study has shown that NSD2 regulates glucose metabolism; however, whether NSD2 serves roles in diabetes has not been thoroughly elucidated to date. In present study, the expression of NSD2 in blood samples from patients with T2DM was compared with that in healthy volunteers. Notably, the expression of NSD2 was negatively correlated with glucose concentration but positively associated with PDX1 expression. Several functional experiments, including CCK-8 assay and colony formation assay, revealed that NSD2 promoted the proliferation of pancreatic $\beta$ cell lines. Moreover, ectopic expression of NSD2 significantly promoted insulin secretion. In addition, NSD2 served as a transfection factor and it was identified that NSD2 transcriptionally regulated PDX1 expression through its H3K36me2 methyltransferase activity. The present study indicated that NSD2 may be a novel molecular therapy target of T2DM.
\end{abstract}

\section{Introduction}

Diabetes has become a major public health issue in the world, associating with increased micro- or macro-vascular disease, disability and premature mortality (1-4). Type 2 diabetes mellitus (T2DM), also known as non-insulin-dependent

Correspondence to: Dr LiliZheng, Department of Endocrinology, The First Affiliated Hospital of Zhengzhou University, 1 Jianshedong Road, Zhengzhou, Henan 450052, P.R. China E-mail: 1ili1203z@163.com

Key words: NSD2, type 2 diabetes mellitus (T2DM), proliferation, insulin secretion, pancreatic and duodenal homeobox 1 (PDX1) diabetes mellitus, mainly disrupts the normal action and secretion of insulin in the body (5). This can lead to a series of severe syndromes, including hypertension, cardiovascular disease and increased risk of cancer (6). $\beta$ cells apoptosis and insulin secretory dysfunction are happened in T2DM (7-11), resulting in an inability to compensate for insulin resistance. Therefore, it is necessary to discover a strategy to facilitate $\beta$ cell proliferation and increase insulin secretory.

Nuclear receptor-binding SET domain protein 2 (NSD2), also known as Wolf-Hirschhorn syndrome candidate 1 (WHSC1) or multiple myeloma SET domain (MMSET), together with NSD1 and NSD3, belongs to the SET histone methyltransferase family $(12,13)$. As a transcription factor, NSD2 mediates H3K36 dimethylation and trimethylation, or H4K20 dimethylation $(14,15)$. Previous studies have shown that NSD2 is up-regulated in multiple types of human cancers, including small-cell lung cancers, stomach cancer, neuroblastoma, colon cancer, hepatocellular carcinoma, ovarian carcinoma and prostate cancer (16-22). Furthermore, NSD2 has been demonstrated to support the proliferation and/or survival of many cancer cell lines, such as prostate cancer (22-24), myeloma cell lines with $\mathrm{t}(4 ; 14)$ translocations $(25-28)$ and leukemia cell lines carrying the E1099K mutation (29), Wang et al (30) has found that NSD2 regulates glucose metabolism; however, whether NSD2 plays roles in diabetes has not been explored.

Here, we found that NSD2 was down-regulated in T2DM. Down-regulation of NSD2 was associated with elevated glucose level. Moreover, NSD2 promoted $\beta$ cell lines proliferation and insulin secretion. NSD2 as a transcription factor, we found that it transcriptionally regulated PDX1 expression.

\section{Materials and methods}

Cell culture. INS-1 and MIN6 cells were purchased from ATCC (Manassas, VA, USA) and cultured in $5 \mathrm{mmol} / 1$ glucose DMEM (HyClone; GE Healthcare Life Sciences, Logan, UT, USA) supplemented with $10 \%$ horse serum (Invitrogen; Thermo Fisher Scientific, Inc., Waltham, MA, USA), 5.5 mM 2-mercaptoethanol, $100 \mathrm{U} / \mathrm{ml}$ penicillin and $0.1 \mathrm{mg} / \mathrm{ml}$ streptomycin (Invitrogen; Thermo Fisher Scientific, Inc.) at $37^{\circ} \mathrm{C}$ with $5 \% \mathrm{CO}_{2}$. 
Blood sample collection. All healthy volunteers and T2DM patients have known and written informed consent before experiments. All human sample experiments have been approved by the Ethics Committee of The First Affiliated Hospital of Zhengzhou University. Blood samples were collected from The First Affiliated Hospital of Zhengzhou University during 2013 to 2017 and stored at $-80^{\circ} \mathrm{C}$ immediately before using.

Cell transfection. The INS-1 and MIN6 cells were placed into a 6 -well plate (a density of $4 \times 10^{5}$ cells/well) and grown to $70-80 \%$ confluence. The cells were then transfected with $2.5 \mu \mathrm{g}$ plasmid or $50 \mathrm{nM}$ siRNAs using Lipofectamine 2000 according to manufacturer's instruction (Invitrogen; Thermo Fisher Scientific, Inc.). After transfection for 48 h, cells were collected and used to further experiments. The sequences of siRNA as followed: Scramble siRNA (SCR): 5'-UUCUCCGAA CGUGUCACGU-3'; NSD2 siRNA\#1: 5'-TGGAGCACACGA AGCACCA-3'; NSD2 siRNA\#2: 5'-TGTCCAGGAACGCTG AGCT-3'; PDX siRNA: 5'-TCCAAAACCGCCGCATGAAGT GG-3'. The vector plasmid (pcDNA3.1), pcDNA3.1-NSD2 and pcDNA3.1-PDX1 were purchased from Vigene Biosciences Co., Ltd., (Shandong, China).

Reverse transcription- quantitative polymerase chain reaction $(R T-q P C R)$. Total RNA was extracted from human blood samples and transfected cells using TRIzol (Invitrogen; Thermo Fisher Scientific, Inc.). cDNA was prepared using a PrimeScript TM RT reagent kit (Takara Bio, Inc., Otsu, Japan) according to manufacturer's instruction. Subsequently, SYBR green PCR mix (Roche Diagnostics GmbH, Mannheim, Germany) was used to perform qRT-PCR assay according to the manufacturer's protocol. GAPDH was used as an endogenous control. The primer sequences were as follows: NSD2 forward primer: 5'-TGTAAACCACTGAAGAAGCGA-3', reverse primer: 5'-GTCCGAGACCTCATTCTCAG-3'; PDX1 forward primer: 5'-CCTTTCCCATGGATGAAGTC-3' and reverse primer: 5'-AACCAGATCTTGATGTGTCTC-3'; GAPDH forward primer: 5'-TCTCTGATTTGGTCGTAT TGG-3' and reverse primer: 5'-CATGTAAACCATGTAGTT GAGGTC-3'. The relative mRNA expression was normalized to GAPDH and measured using $2^{-\Delta \Delta \mathrm{Ct}}(31)$. Each independent experiment was performed in triplicate.

Western blotting. Whole protein was prepared from transfected cells using RIPA lysis buffer (Beyotime Institute of Biotechnology, Haimen, China) with $1 \%$ cocktail (Roche Diagnostics $\mathrm{GmbH}$ ). The concentration of protein was measured using a BCA kit (Pierce; Thermo Fisher Scientific, Inc.) according to manufacturer's instruction. Approximately $40 \mu \mathrm{g}$ proteins were separated on a $10 \%$ SDS-PAGE and transferred to a nitrocellulose (NC) membrane. Following by incubation with $5 \%$ skimmed milk at room temperature for $1 \mathrm{~h}$, the membranes were incubated with primary antibodies at $4^{\circ} \mathrm{C}$ overnight. The antibodies as followed: NSD2 (1:1,000; cat. no. 75359), PDX1 (1:2,000; cat. no. 47267), $\beta$-actin (1:5,000; cat. no. 8226; all from Abcam, Cambridge, MA, USA). The membranes were washed with TBST three times, and incubated with secondary horseradish peroxidase (HRP)-conjugated antibodies (1:5,000; cat. no. 6789 and 6721; Abcam, Cambridge, MA, USA) at room temperature for $1 \mathrm{~h}$. After washing with
TBST three times, the blots were visualized using ECL kit. Each independent experiment was performed in triplicate.

CCK-8 cell viability assay. NSD2 was overexpressed or knocked down in INS-1 and MIN6 cells, $24 \mathrm{~h}$ after transfection, approximately $2 \times 10^{3}$ cells were placed into a 96 -well with three wells for each group. The cells were maintained in an incubator with a $5 \% \mathrm{CO}_{2}$ atmosphere at $37^{\circ} \mathrm{C}$. At $0,24,48$ and 72 h, $20 \mu \mathrm{l} \mathrm{CCK}-8$ solution was added into medium, and incubated with cells at $37^{\circ} \mathrm{C}$ for $1 \mathrm{~h}$. The absorbance was measured at $450 \mathrm{~nm}$ with a microplate reader (BioTek Instruments, Inc., Winooski, VT, USA). The effect of NSD2 on cell growth and cell viability was determined. Each independent experiment was performed in triplicate.

Colony formation assay. After transfection for $48 \mathrm{~h}$, approximately $5 \times 10^{4}$ INS-1 or MINE6 cells were placed into 6-well plates, and cultured with serum-free DMEM. After incubating for two weeks, cells were fixed with $4 \%$ paraformaldehyde solution at room temperature for $15 \mathrm{~min}$ and stained with $0.1 \%$ crystal violet (Sigma-Aldrich; Merck KGaA, Darmstadt, Germany) at room temperature for $15 \mathrm{~min}$. The number of colonies were counted under a light microscope. Each independent experiment was performed in triplicate.

Insulin secretion and insulin content measurements. NSD2 was overexpressed or knocked down in INS-1 and MIN6, after transfection for $48 \mathrm{~h}$, approximately $3.5 \times 10^{5}$ cells were placed in a 24-well plate. Cells were washed with SAB (secretion assay buffer, $0.2 \% \mathrm{BSA}, 2.5 \mathrm{mM} \mathrm{CaCl}_{2}, 25.5 \mathrm{mM} \mathrm{NaHCO}$, $4.7 \mathrm{mM} \mathrm{KCl,} 20 \mathrm{mM}$ HEPES (pH 7.2), $1.2 \mathrm{mM} \mathrm{KH}_{2} \mathrm{PO}_{4}$, $1.16 \mathrm{mM} \mathrm{MgSO}_{4}, 2.8 \mathrm{mM}$ glucose and $114 \mathrm{mM} \mathrm{NaCl}$ ) for three times. Next, cells were incubated with $1.5 \mathrm{ml} \mathrm{SAB}$ at $37^{\circ} \mathrm{C}$ with $5 \% \mathrm{CO}_{2}$. Immediately after incubation, a Coat-A-Count insulin RIA kit (Diagnostic Products Corp., Los Angeles, CA, USA) was used to measure insulin secretion according to the manufacturer's instruction. Subsequently, cells were lysed with RIPA buffer (50 mM Tris $\mathrm{HCl}$ pH 8, $150 \mathrm{mM} \mathrm{NaCl}$, $1 \%$ NP-40/Triton X, $0.1 \%$ SDS, $0.5 \%$ sodium deoxycholate, $2 \mathrm{mM}$ EDTA and $50 \mathrm{mM} \mathrm{NaF}$ ). The supernatant of lysate was collected and the protein concentration was measured. The insulin secretion was normalized by protein concentration. Each independent experiment was performed in triplicate.

ChIP and $q$ ChIP assay. A ChIP assay was performed with $3 \mu$ g goat anti-rabbit IgG (cat. no. ab171870; Abcam), anti-NSD2 (cat. no. ab75359; Abcam) and anti-H3K36me2 (cat. no. ab9043; Abcam) using a ChIP assay kit (Beyotime Institute of Biotechnology) according to the manufacturer's instructions. The antibody-bound DNA was used to perform qChIP. SYBR green Mix (Roche Diagnostics GmbH) was used to perform RT-qPCR. The thermocycling conditions were as follows: 30 cycles of denaturation at $95^{\circ} \mathrm{C}$ for $5 \mathrm{~min}$, annealing at $57^{\circ} \mathrm{C}$ for $30 \mathrm{sec}$ followed by extension at $72^{\circ} \mathrm{C}$ for $5 \mathrm{~min}$. The following primers were used: PDX1 forward primer: 5'-AGGGTCTCATTCTGTCGTTC-3' and reverse primer: 5'-GCCTGTAATCCCAGCTACTC-3'. The fold of enrichment was normalized to that of $\operatorname{IgG}$ and quantified using the $2^{-\Delta \Delta \mathrm{Ct}}$ method. Each independent experiment was performed in triplicate. 
A

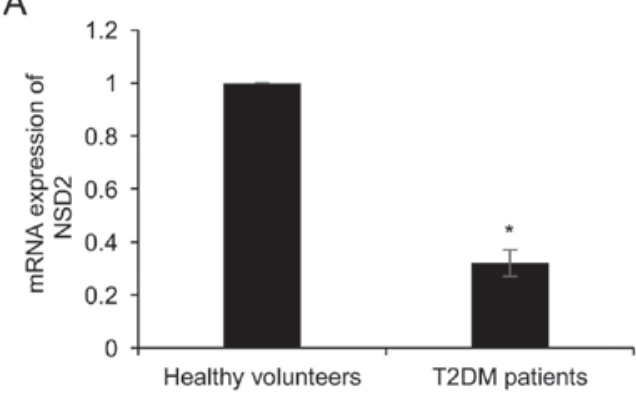

B

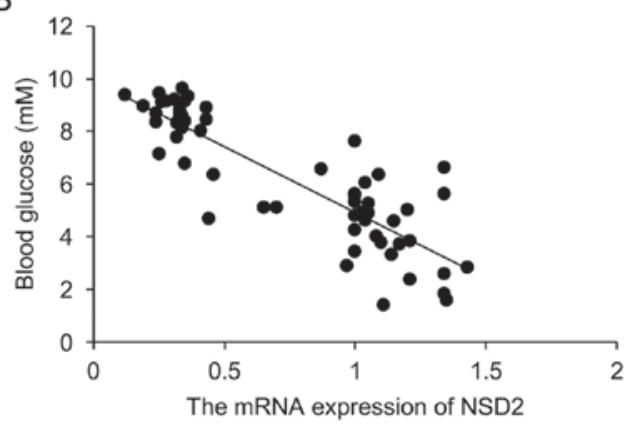

Figure 1. NSD2 expression is downregulated in T2DM. (A) The expression of NSD2 in T2D patients and healthy volunteers' plasma were assessed using RT-qPCR. * $\mathrm{P}<0.05$ vs. healthy volunteers. (B) The association between the NSD2 expression and blood glucose levels in T2DM patients were determined using Pearson's correlation analysis. T2DM, type 2 diabetes mellitus.

Luciferase reporter assay. The promoter region $(-2000$ to +200$)$ of PDX1 were cloned into pGL3 luciferase vector (Invitrogen; Thermo Fisher Scientific, Inc.). For the luciferase assay, INS-1 and MIN6 cells were co-transfected with pGL3-slug, renilla and NSD2 or vector. After transfection for $24 \mathrm{~h}$, luciferase reporter assay was performed using a dual-luciferase reporter assay kit according to manuscript's protocol (Promega Corporation, Madison, WI, USA). The Renilla luciferase activity was used to normalize firefly luciferase activity. Each independent experiment was performed in triplicate.

Statistical analysis. Each independent experiment was performed in triplicate for statistical analysis. The data are presented as the mean \pm SD. All data were analyzed using GraphPad Prism v.5.01 (GraphPad Software, Inc., La Jolla, CA, USA). The correlation between the clinic pathological features of T2DM patient and NSD2 expression was analyzed by $\chi^{2}$ test. One-way ANOVA and Tukey test were used to analyze the difference between multiple comparisons. Two-tailed Student t-test was used to analyze the difference between two groups. The correlation of blood glucose levels and NSD2 expression was determined by Pearson's correlation coefficient. $\mathrm{P}<0.05$ was considered to indicate a statistically significant difference.

\section{Results}

NSD2 expression is down-regulated in T2DM. To explore the underlying mechanism of NSD2 in T2DM, we collected the plasma from $58 \mathrm{~T} 2 \mathrm{DM}$ patients and 58 healthy volunteers, and detected the expression of NSD2. As shown in Fig. 1A, the expression of NSD2 in T2DM patients was less than that in healthy volunteers group (Fig. 1A). Moreover, the association between NSD2 expression and patient clinical information was analyzed, we found that the expression NSD2 had no correlation with age and gender (Table I). Furthermore, we found that the NSD2 expression was negatively associated with the glucose concentration ( $\mathrm{r}=0.81$; Fig. $1 \mathrm{~B})$.

NSD2 promotes the proliferation of pancreatic $\beta$ cell lines and the insulin secretion. In order to further decipher the role of NSD2 in diabetes, we overexpressed or knocked down NSD2 in two pancreatic $\beta$ cell lines INS-1 and MIN6. The NSD2 expression was detected by western blotting and qRT-PCR, respectively. The results revealed transfection with plasmids
Table I. Clinicopathologic variables in 58 patients with T2DM.

\begin{tabular}{lcccc}
\hline & \multicolumn{4}{c}{$\begin{array}{c}\text { NSD2 protein } \\
\text { expression }\end{array}$} \\
\cline { 3 - 4 } & $\begin{array}{c}\text { No. } \\
\text { Variables }\end{array}$ & $\begin{array}{c}\text { Low } \\
(\mathrm{n}=58)\end{array}$ & $\begin{array}{c}\text { High } \\
(\mathrm{n}=18)\end{array}$ & P-value \\
\hline Age & & & & 0.509 \\
$<35$ & 35 & 23 & 12 & \\
$\geq 35$ & 23 & 17 & 6 & \\
Sex & & & & 0.724 \\
Male & 27 & 18 & 9 & \\
Female & 31 & 22 & 9 & \\
Glucose & & & & 0.040 \\
concentration & & & & \\
$<7.0$ mM & 21 & 11 & 10 & \\
$>7.0$ mM & 37 & 29 & 8 & \\
PDX1 expression & & & & \\
Low & 37 & 30 & 7 & \\
High & 21 & 10 & 11 & \\
\hline
\end{tabular}

T2DM, type 2 diabetes mellitus.

expressing NSD2 increased two-fold NSD2 levels in INS-1 and MIN6 cells, and NSD2 expression was decreased followed by transfected with NSD2 siRNA (siNSD2) (Fig. 2A and B). Subsequently, CCK-8 analysis was performed to determine the function of NSD2 on cellular proliferation in pancreatic $\beta$ cell lines, suggesting that ectopic expression of NSD2 obviously facilitated the proliferation rate of INS-1 and MIN6 cells, compared to the control group; however, inhibition of NSD2 significantly led to a decrease of proliferation rate of INS-1 and MIN6 cells, compared to the control group (Fig. 2C). Moreover, similar results were observed in colony formation assay, suggesting that compared to the control groups, ectopic regulation of NSD2 resulted in an elevated number of colonies in INS-1 and MIN6 cells (Fig. 2D). Meanwhile, NSD2 inhibition decreased the number of colonies in INS-1 and MIN6 cells, compared to the control groups (Fig. 2D). In addition, in response to glucose stimulation, we found that 
A

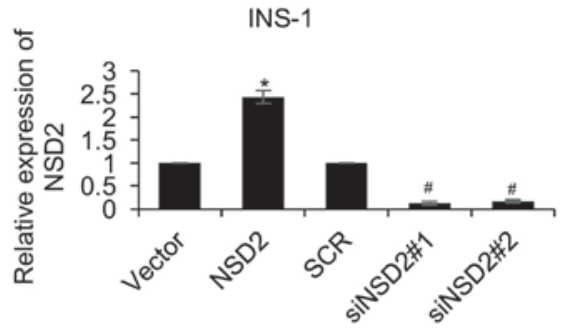

B

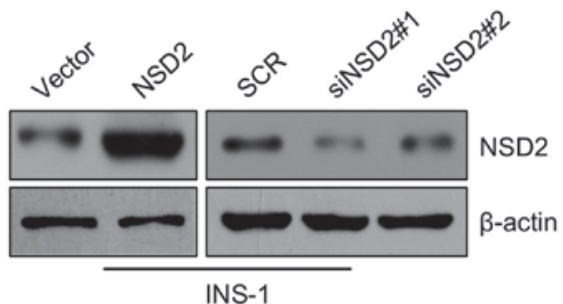

C

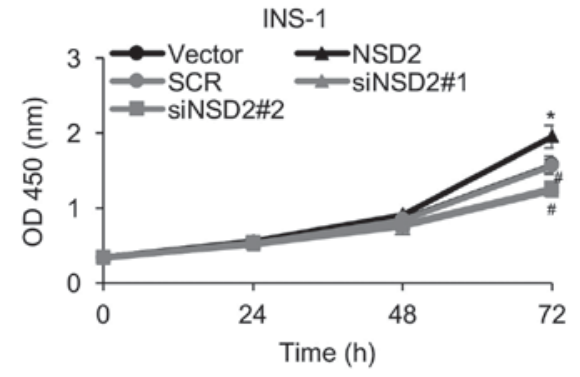

D

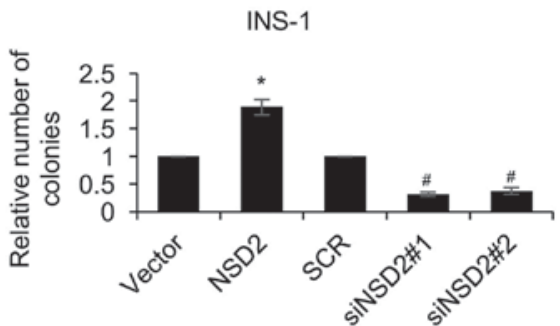

E

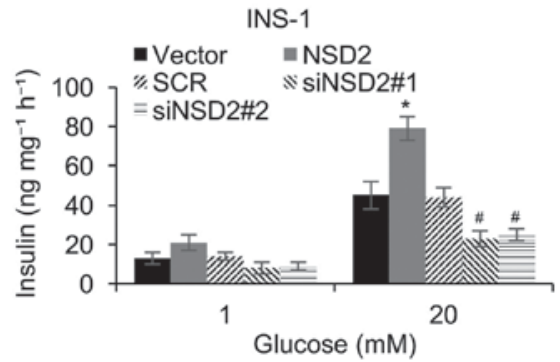

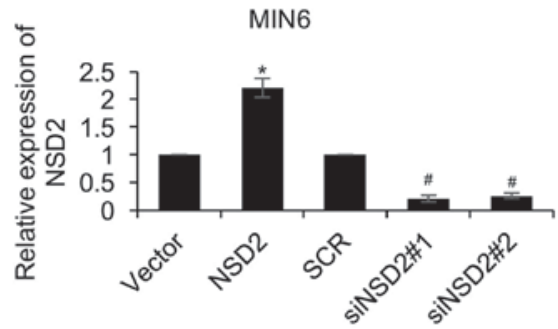
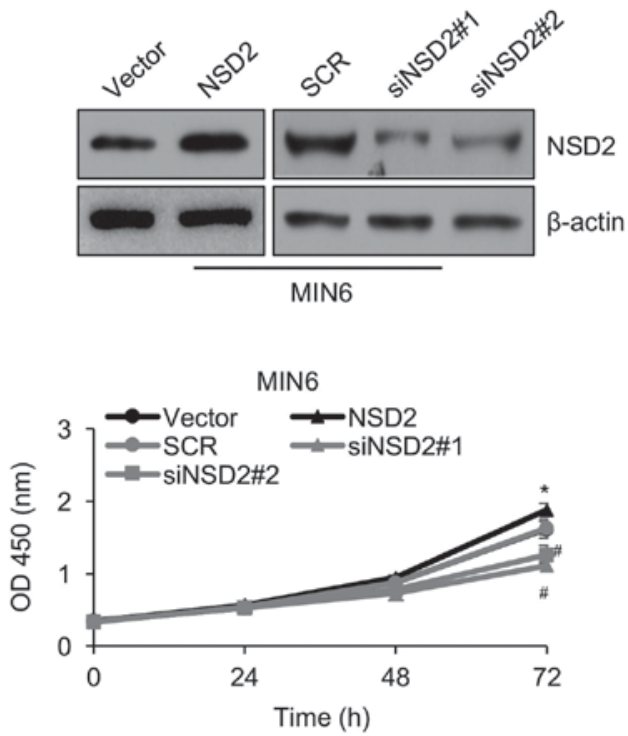

MIN6
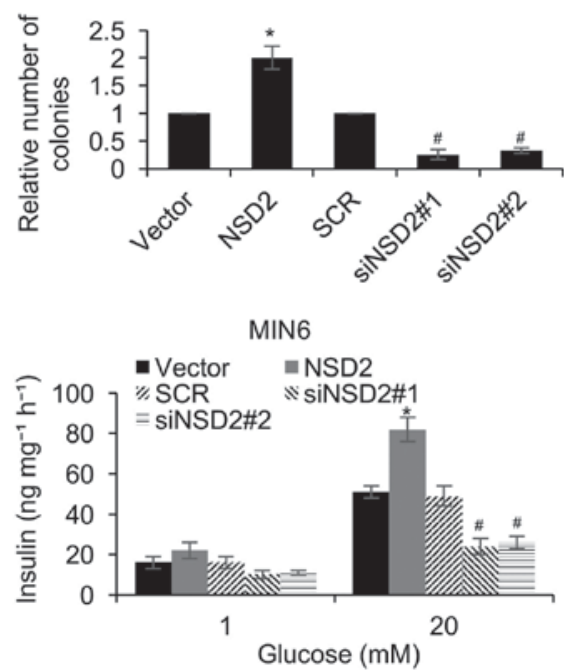

Figure 2. NSD2 promotes the proliferation of pancreatic $\beta$ cell lines and the insulin secretion. (A and B) NSD2 was overexpressed or knocked down in INS-1 and MIN6 cells. After transfection for $48 \mathrm{~h}$, the mRNA expression of NSD2 was determined using qRT-PCR and western blotting analyses, respectively. "P $<0.05$ vs. vector or SCR. (C) CCK-8 assay was performed to assess the effect of NSD2 on cell proliferation. " $\mathrm{P}<0.05$ vs. vector or SCR. (D) Colony formation assay was performed to assess the effect of NSD2 on cell proliferation. " $\mathrm{P}<0.05$ vs. vector or SCR. (E) NSD2 was overexpressed or knocked down in INS-1 and MIN6 cells. After transfection for 48 h, INS-1 and MIN6 cells were incubated with 1 or $20 \mathrm{mM}$ glucose for 90 min and the rate of insulin secretion was detected in each group. "P<0.05 NSD2 vs. vector or SCR.

ectopic expression of NSD2 remarkably improved the insulin secretion (Fig. 2E); however, inhibition of NSD2 significantly suppressed insulin secretion (Fig. 2E). Our findings suggest that NSD 2 facilitates the proliferation of pancreatic $\beta$ cell lines and the insulin secretion.

NSD2 transcriptionally regulates $P D X 1$ through its histone methylation activity in diabetes. As a histone methylase, NSD2 has been reported to regulate gene expression. Moreover, PDX1 has been reported to play key roles in diabetes (32). Because we found NSD2 regulated pancreatic $\beta$ cells proliferation and insulin secretion, we assumed that NSD2 might regulate PDX1 expression in diabetes. To verify our hypothesis, we detected the expression of PDX1 after overexpression or knockdown NSD2 in INS-1 and MIN6 cells. The results of western blotting and qRT-PCR analyses demonstrated that ectopic 
A

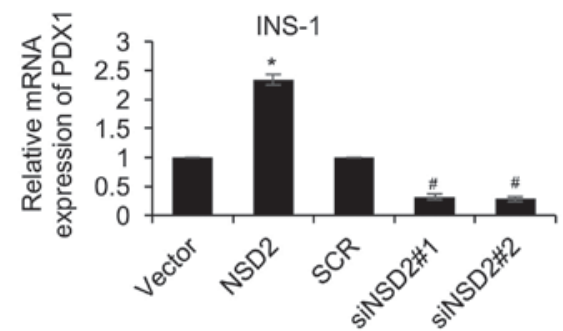

B

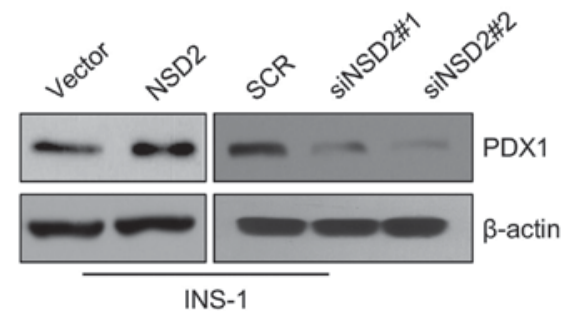

C

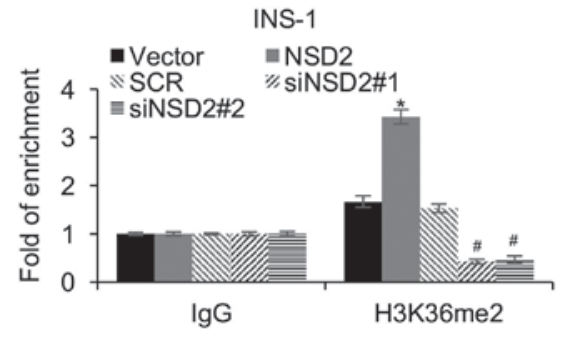

INS-1
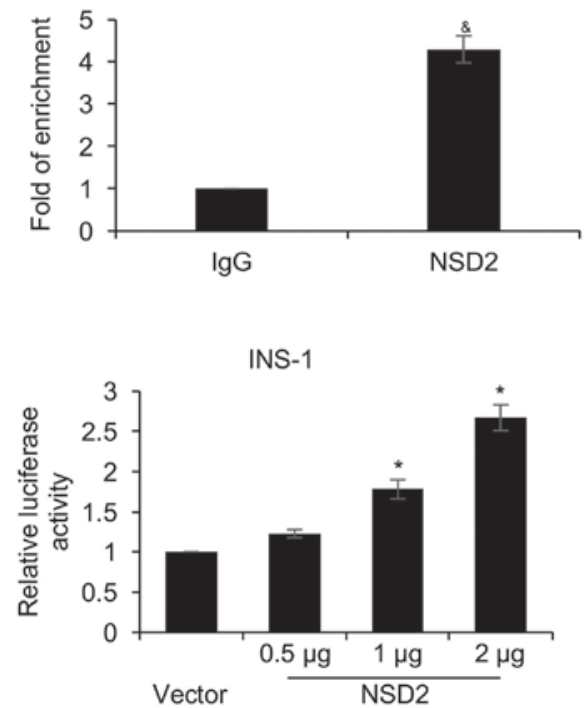
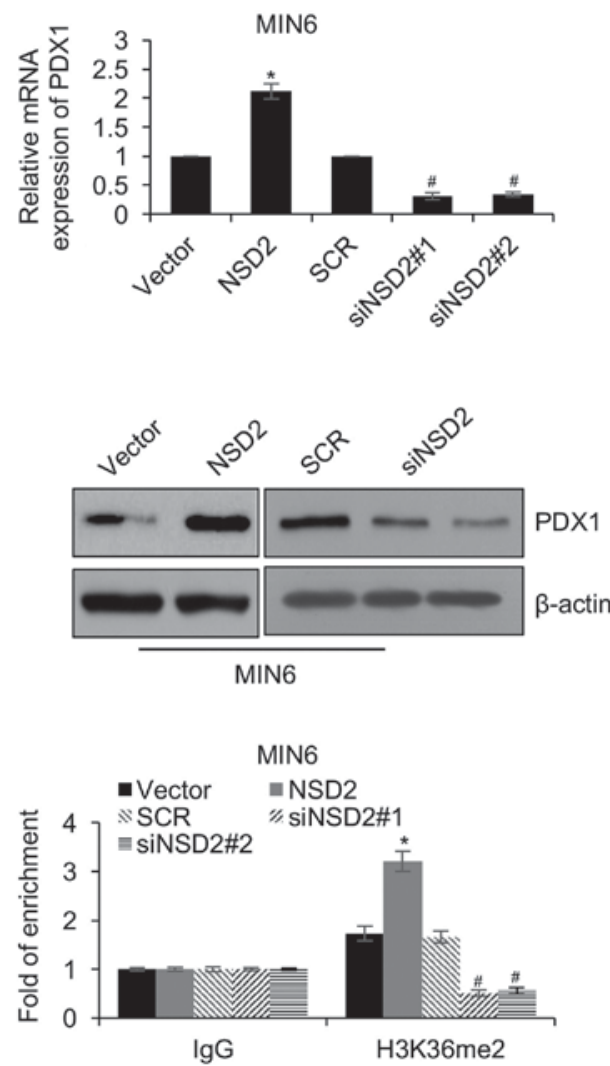

MIN6

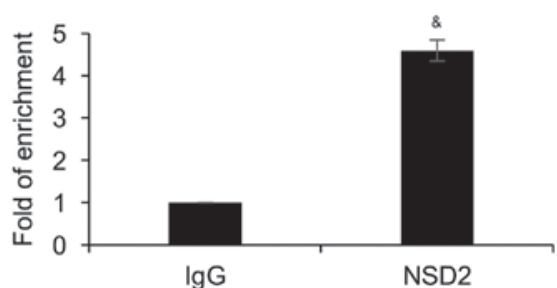

MIN6

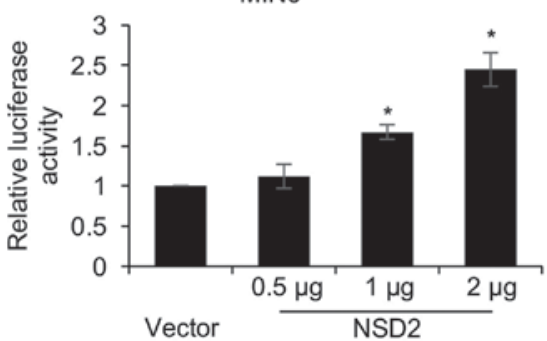

Figure 3. NSD2 transcriptionally regulates PDX1 through its histone methylation activity in diabetes. (A and B) NSD2 was overexpressed or knocked down in INS-1 and MIN6 cells. After transfection for $48 \mathrm{~h}$, the mRNA and protein levels of PDX1 were detected using qRT-PCR and western blotting analyses, respectively. "P<0.05 NSD2 vs. vector or SCR. (C) NSD2 was overexpressed or knocked down in INS-1 and MIN6 cells, and ChIP and qChIP assay was performed using anti-H3K36me2 antibody and anti-NSD2 antibody. "P<0.05 NSD2 vs. vector or SCR. (D) NSD2 was overexpressed or knocked down in INS-1 and MIN6 cells, dual luciferase assay was performed. "P<0.05 NSD2 vs. vector.

expression of NSD2 significantly increased PDX1 expression, and knockdown of NSD2 obviously decreased PDX1 expression (Fig. 3A and B). That both protein and mRNA levels of PDX1 were regulated by NSD2 indicated that PDX1 might be regulated by NSD2 at transcription level. Subsequently, ChIP and qChIP assay was performed to determine whether NSD2 transcriptionally regulated PDX1 expression through methylating H3K36, showing that the occupation of H3K36me2 at the promoter region of $P D X 1$ was obviously increased while NSD2 was overexpressed (Fig. 3C); however, the occupation of $\mathrm{H} 3 \mathrm{~K} 36 \mathrm{me} 2$ at the promoter region of $P D X 1$ was obviously decreased while NSD2 was knocked down (Fig. 3C). Additionally, we found that NSD2 could bind the promoter region of PDX1 (Fig. 3C). The similar results were observed in MIN6 cells (Fig. 3C). Moreover, dual luciferase reporter assay comfirmed that NSD2 transcriptionally activated PDX1 


\section{A \\ B}
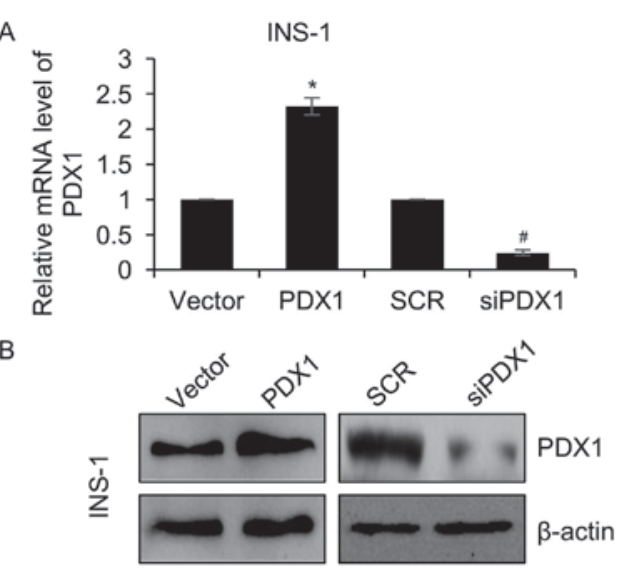

C

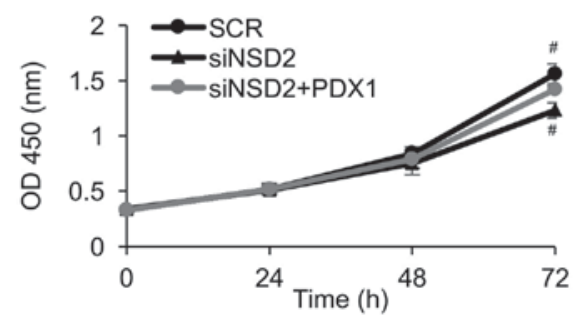

INS-1

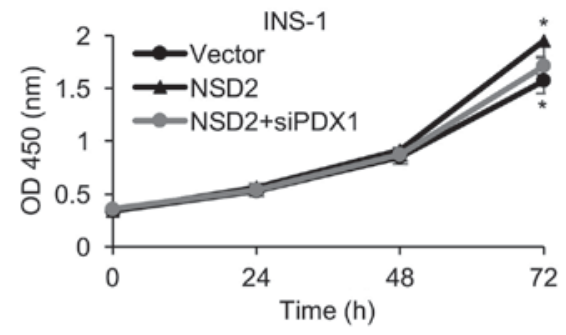

D
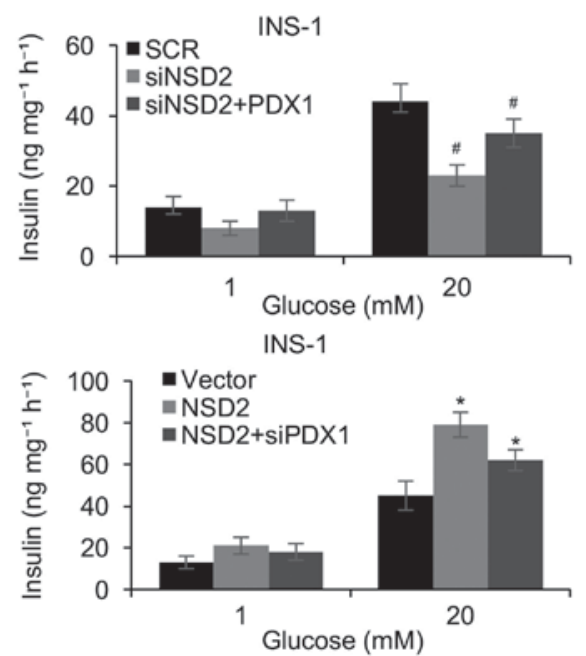
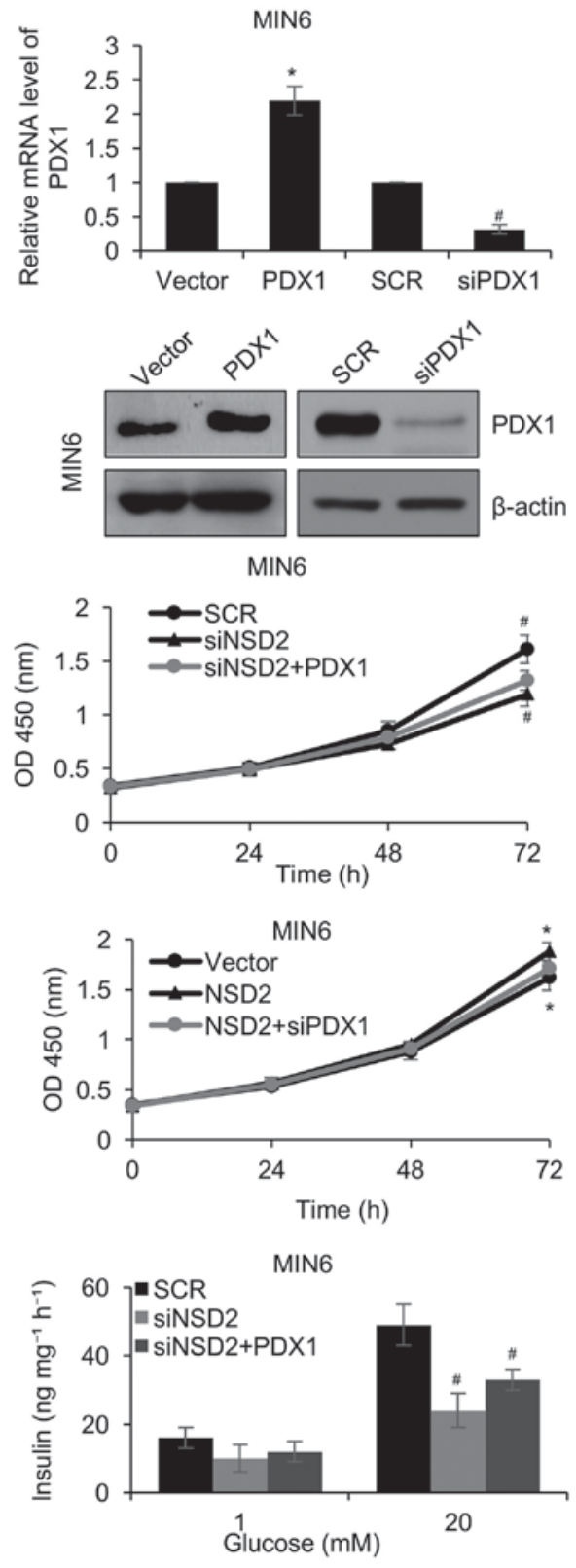

MIN6

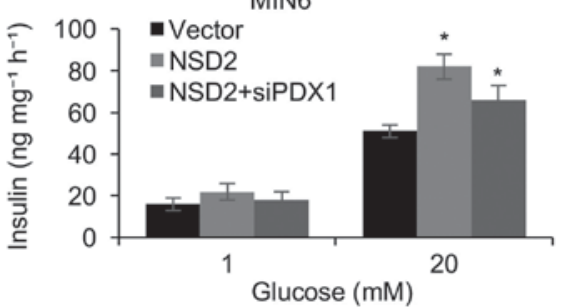

Figure 4. PDX1 is involved in the NSD2-mediated insulin secretion and pancreatic $\beta$ cells proliferation. (A and B) PDX1 was overexpressed or knocked down in INS-1 and MIN6 cells. After transfection for $48 \mathrm{~h}$, the mRNA and protein levels of PDX1 were detected using qRT-PCR and western blotting analyses, respectively. "P<0.05 vs. vector or SCR. (C) PDX1 was overexpressed in siNSD2-INS-1 and siNSD2-MIN6 cells or was knocked down in NSD2-INS-1 cells and NDS2-MIN6 cells. After transfection for $48 \mathrm{~h}$, CCK- 8 assay was performed to assess the effect of NSD2 and PDX1 on cell proliferation. "P $<0.05$ vs. vector or SCR. (D) PDX1 was overexpressed in siNSD2-INS-1 and siNSD2-MIN6 cells or was knocked down in NSD2-INS-1 cells and NDS2-MIN6 cells. After transfection for $48 \mathrm{~h}$, INS-1 and MIN6 cells were incubated with 1 or $20 \mathrm{mM}$ glucose for $90 \mathrm{~min}$ and the rate of insulin secretion was detected in each group. ${ }^{*} \mathrm{P}<0.05$ vs. vector or SCR.

(Fig. 3D). In addition, we found PDX1 expression in the plasma from T2DM patients was less than that in healthy volunteers, positively correlated with NSD2 expression (Table I). These results reveal that NSD2 transcriptionally regulates PDX1 through its histone methylation activity in diabetes.
PDX1 is involved in the NSD2-mediated insulin secretion and pancreatic $\beta$ cells proliferation. Because PDX1 was transcriptionally regulated by NSD2, so we hypothesized that NSD2 facilitated pancreatic $\beta$ cells proliferation and insulin secretion through regulation of PDX1. In order to 
verify our hypothesis, we overexpressed or knocked down of PDX1 in INS-1 and MIN6 cells. Western blotting and qRT-PCR analyses were used to determine the protein and mRNA levels of PDX1, respectively. The results of western blotting and qRT-PCR analyses revealed that both protein and mRNA levels of PDX1 were obviously increased approximately 2.4-fold in the INS-1 and MIN6 cells transfected with FLAG-PDX1 plasmid, and decreased following PDX1 siRNA (Fig. 4A and B). Subsequently, we explored whether PDX1 involved in the NSD2-mediated pancreatic $\beta$ cell proliferation and insulin secretion. As shown in Fig. 4C, the CCK-8 assay revealed that ectopic expression of PDX1 significantly rescued the effect of the NSD2 inhibition on pancreatic $\beta$ cells proliferation (Fig. 4C). Meanwhile, inhibition of PDX1 significantly impaired the effect of the NSD2 overexpression on pancreatic $\beta$ cells proliferation (Fig. 4C). Similarly, overexpression of PDX1 also rescued the effect of NSD2 inhibition on glucose-stimulated insulin secretion, and inhibition of PDX1 significantly impaired the effect of the NSD2 overexpression on glucose-stimulated insulin secretion (Fig. 4D). To sum up, our work show that PDX1 is a downstream target of NSD2, and NSD 2 promotes the proliferation of pancreatic $\beta$ cell lines and the insulin secretion through regulation of PDX1.

\section{Discussion}

Previous studies have shown that NSD2 was the up-regulated in multiple types of human cancers (16-22). However, the role of NSD2 in T2DM has still not been elucidated.

Here, we found that NSD2 was down-regulated in T2DM patients, compared with healthy volunteers group. Moreover, the expression of NSD2 was negatively associated with high blood glucose levels, suggesting NSD2 might play a key role in T2DM. Previous work has found that NSD2 regulates glucose metabolism (30). To further consider the effect of NSD2 in T2DM, we used two pancreatic $\beta$ cell lines, such as INS-1 and MIN6. NSD2 has been reported to promote cell proliferation in several cancers (22-24). Here, CCK8 assay and colony formation assay demonstrated that ectopic expression of NSD2 facilitated the proliferation of INS-1 and MIN6 cells. Knockdown of NSD2 suppressed the proliferation of INS-1 and MIN6 cells. Furthermore, the secretion of insulin also regulated by NSD2.

PDX1 has been reported to play fundamental roles in diabetes mellitus, abnormal expression of PDX1 suppressed pancreatic $\beta$ cell proliferation $(32,33)$. NSD2 as transcription factor, we assumed NSD2 might transcriptionally regulated PDX1 in pancreatic $\beta$ cell lines. ChIP and qChIP assay as well as luciferase assay suggested PDX1 was transcriptionally activated by NSD2 through its H3K36me2 methylation activity. Furthermore, we found that NSD2 promoted pancreatic $\beta$ cell lines proliferation and insulin secretion through regulation of PDX1.

Here, our study still has some limitation, we admire that it is better to detect the expression of NSD2 in T2DM patients' and health volunteers' pancreatic $\beta$ cells, but we don't have enough samples to do it. Moreover, it is necessary to specific overexpression of NSD2 in mice pancreatic tissues and further determine the roles of NSD2 in vivo. Furthermore, more downstream target of NSD2 need be detected using ChIP-seq assay, it might further uncover the function of NSD2.
Collectively, the current study revealed the mechanisms of NSD2 on pancreatic $\beta$ cell proliferation and insulin secretion in T2DM. We suggested NSD2 as a novel molecular therapy target of T2DM.

\section{Acknowledgements}

Not applicable.

\section{Funding}

No funding was received.

\section{Availability of data and materials}

The analyzed data sets generated during the present study are available from the corresponding author on reasonable request.

\section{Authors' contributions}

LLZ and SS conceived and designed the work. SS and LZ constructed expression plasmids, prepared proteins, and performed experiments. SS and LZ analyzed the data. SS and LLZ wrote the paper.

\section{Ethics approval and consent to participate}

The present study was approved by the Ethics Committee of The First Affiliated Hospital of Zhengzhou University, and written informed consent was provided from patients and healthy volunteers prior to enrolment.

\section{Patient consent for publication}

Not applicable.

\section{Competing interests}

The authors declare that they have no competing interests.

\section{References}

1. Gustafson B: Adipose tissue, inflammation and atherosclerosis. J Atheroscler Thromb 17: 332-341, 2010.

2. Donath MY, Storling J, Berchtold LA, Billestrup N and Mandrup-Poulsen T: Cytokines and beta-cell biology: From concept to clinical translation. Endocr Rev 29: 334-350, 2008.

3. Berk BC, Weintraub WS and Alexander RW: Elevation of C-reactive protein in 'active' coronary artery disease. Am J Cardiol 65: 168-172, 1990.

4. Ridker PM, Cushman M, Stampfer MJ, Tracy RP and Hennekens $\mathrm{CH}$ : Inflammation, aspirin and the risk of cardiovascular disease in apparently healthy men. N Engl J Med 336: 973-979, 1997.

5. Inzucchi SE, Bergenstal RM, Buse JB, Diamant M, Ferrannini E, Nauck M, Peters AL, Tsapas A, Wender R, Matthews DR, et al: Management of hyperglycemia in type 2 diabetes: A patient-centered approach: Position statement of the American Diabetes Association (ADA) and the European Association for the Study of Diabetes (EASD). Diabetes Care 35: 1364-1379, 2012.

6. Yerlikaya $\mathrm{O}$, Acu M and Kinik O: Importance of dairy products in cardiovascular diseases and type 2 diabetes. Crit Rev Food Sci Nutr 53: 902-908, 2013.

7. Stoffers DA: The development of beta-cell mass: Recent progress and potential role of GLP-1. Horm Metab Res 36: 811-821, 2004. 
8. Tourrel C, Bailbe D, Lacorne M, Meile MJ, Kergoat M and Portha B: Persistent improvement of type 2 diabetes in the Goto-Kakizaki rat model by expansion of the beta-cell mass during the prediabetic period with glucagon-like peptide-1 or exendin-4. Diabetes 51: 1443-1452, 2002.

9. Sakuraba H, Mizukami H, Yagihashi N, Wada R, Hanyu C and Yagihashi S: Reduced beta-cell mass and expression of oxidative stress-related DNA damage in the islet of Japanese Type II diabetic patients. Diabetologia 45: 85-96, 2002.

10. Marchetti P, Del Guerra S, Marselli L, Lupi R, Masini M, Pollera M, Bugliani M, Boggi U, Vistoli F, Mosca F and Del Prato S: Pancreatic islets from type 2 diabetic patients have functional defects and increased apoptosis that are ameliorated by metformin. J Clin Endocrinol Metab 89: 5535-5541, 2004

11. Cozar-Castellano I, Fiaschi-Taesch N, Bigatel TA, Takane KK, Garcia-Ocaña A, Vasavada R and Stewart AF: Molecular control of cell cycle progression in the pancreatic beta-cell. Endocr Rev 27: 356-370, 2006.

12. Jablecka A, Bogdanski P, Balcer N, Cieslewicz A, Skoluda A and Musialik K: The effect of oral L-arginine supplementation on fasting glucose, HbAlc, nitric oxide and total antioxidant status in diabetic patients with atherosclerotic peripheral arterial disease of lower extremities. Eur Rev Med Pharmacol Sci 16 : 342-350, 2012

13. Hollink IH, van den Heuvel-Eibrink MM, Arentsen-Peters ST, Pratcorona M, Abbas S, Kuipers JE, van Galen JF, Beverloo HB, Sonneveld E, Kaspers GJ, et al: NUP98/NSD1 characterizes a novel poor prognostic group in acute myeloid leukemia with a distinct HOX gene expression pattern. Blood 118: 3645-3656, 2011

14. Li Y, Trojer P, Xu CF, Cheung P, Kuo A, Drury WJ III, Qiao Q, Neubert TA, Xu RM, Gozani O and Reinberg D: The target of the NSD family of histone lysine methyltransferases depends on the nature of the substrate. J Biol Chem 284: 34283-34295, 2009.

15. Morishita M, Mevius D and di Luccio E: In vitro histone lysine methylation by NSD1, NSD2/MMSET/WHSC1 and NSD3/WHSC1L. BMC Struct Biol 14: 25, 2014.

16. Colak H, Uzgur R, Tan E, Hamidi MM, Turkal M and Colak T: Investigation of prevalence and characteristics of mesiodens in a non-syndromic 11256 dental outpatients. Eur Rev Med Pharmacol Sci 17: 2684-2689, 2013.

17. Hudlebusch HR, Skotte J, Santoni-Rugiu E, Zimling ZG, Lees MJ, Simon R, Sauter G, Rota R, De Ioris MA, Quarto M, et al MMSET is highly expressed and associated with aggressiveness in neuroblastoma. Cancer Res 71: 4226-4235, 2011.

18. Toyokawa G, Cho HS, Masuda K, Yamane Y, Yoshimatsu M, Hayami S, Takawa M, Iwai Y, Daigo Y, Tsuchiya E, et al: Histone lysine methyltransferase Wolf-Hirschhorn syndrome candidate 1 is involved in human carcinogenesis through regulation of the Wnt pathway. Neoplasia 13: 887-898, 2011

19. Hudlebusch HR, Santoni-Rugiu E, Simon R, Ralfkiær E, Rossing HH, Johansen JV, Jørgensen M, Sauter G and Helin K: The histone methyltransferase and putative oncoprotein MMSET is overexpressed in a large variety of human tumors. Clin Cancer Res 17: 2919-2933, 2011.

20. Zhou P, Wu LL, Wu KM, Jiang W, Li JD, Zhou LD, Li XY, Chang S, Huang Y, Tan H, et al: Overexpression of MMSET is correlation with poor prognosis in hepatocellular carcinoma. Pathol Oncol Res 19: 303-309, 2013.
21. Yang S, Zhang Y, Meng F, Liu Y, Xia B, Xiao M, Xu Y, Ning X, $\mathrm{Li} \mathrm{H}$ and Lou G: Overexpression of multiple myeloma SET domain (MMSET) is associated with advanced tumor aggressiveness and poor prognosis in serous ovarian carcinoma. Biomarkers 18: 257-263, 2013.

22. Yang P, Guo L, Duan ZJ, Tepper CG, Xue L, Chen X, Kung HJ, Gao AC, Zou JX and Chen HW: Histone methyltransferase NSD2/MMSET mediates constitutive NF-kappaB signaling for cancer cell proliferation, survival and tumor growth via a feed-forward loop. Mol Cell Biol 32: 3121-3131, 2012.

23. Ezponda T, Popovic R, Shah MY, Martinez-Garcia E, Zheng Y, Min DJ, Will C, Neri A, Kelleher NL, Yu J and Licht JD: The histone methyltransferase MMSET/WHSC1 activates TWIST1 to promote an epithelial-mesenchymal transition and invasive properties of prostate cancer. Oncogene 32: 2882-2890, 2013.

24. Asangani IA, Ateeq B, Cao Q, Dodson L, Pandhi M, Kunju LP, Mehra R, Lonigro RJ, Siddiqui J, Palanisamy N, et al: Characterization of the EZH2-MMSET histone methyltransferase regulatory axis in cancer. Mol Cell 49: 80-93, 2013.

25. Kuo AJ, Cheung P, Chen K, Zee BM, Kioi M, Lauring J, Xi Y, Park BH, Shi X, Garcia BA, et al: NSD2 links dimethylation of histone $\mathrm{H} 3$ at lysine 36 to oncogenic programming. Mol Cell 44: 609-620, 2011

26. Lauring J, Abukhdeir AM, Konishi H, Garay JP, Gustin JP, Wang Q, Arceci RJ, Matsui W and Park BH: The multiple myeloma associated MMSET gene contributes to cellular adhesion, clonogenic growth and tumorigenicity. Blood 111: 856-864, 2008.

27. Brito JL, Walker B, Jenner M, Dickens NJ, Brown NJ, Ross FM, Avramidou A, Irving JA, Gonzalez D, Davies FE and Morgan GJ: MMSET deregulation affects cell cycle progression and adhesion regulons in t $(4 ; 14)$ myeloma plasma cells. Haematologica 94: 78-86, 2009.

28. Martinez-Garcia E, Popovic R, Min DJ, Sweet SM, Thomas PM, Zamdborg L, Heffner A, Will C, Lamy L and Staudt LM: The MMSET histone methyl transferase switches global histone methylation and alters gene expression in $\mathrm{t}(4 ; 14)$ multiple myeloma cells. Blood 117: 211-220, 2011.

29. Jaffe JD, Wang Y, Chan HM, Zhang J, Huether R, Kryukov GV, Bhang HE, Taylor JE, Hu M, Englund NP, et al: Global chromatin profiling reveals NSD2 mutations in pediatric acute lymphoblastic leukemia. Nat Genet 45: 1386-1391, 2013.

30. Wang J, Duan Z, Nugent Z, Zou JX, Borowsky AD, Zhang Y, Tepper CG, Li JJ, Fiehn O, Xu J, et al: Reprogramming metabolism by histone methyltransferase NSD2 drives endocrine resistance via coordinated activation of pentose phosphate pathway enzymes. Cancer Lett 378: 69-79, 2016.

31. Livak KJ and Schmittgen TD: Analysis of relative gene expression data using real-time quantitative PCR and the 2(-Delta Delta C(T)) method. Methods 25: 402-408, 2001.

32. Fujitani Y: Transcriptional regulation of pancreas development and $\beta$-cell function [Review]. Endocr J 64: 477-486, 2017.

33. Spaeth JM, Gupte M, Perelis M, Yang YP, Cyphert H, Guo S, Liu JH, Guo M, Bass J, Magnuson MA, et al: Defining a novel role for the PDX1 transcription factor in islet beta cell maturation and proliferation during weaning. Diabetes 66: 2830-2839, 2017. 